\title{
POLITICA COMERCIAL PARA LAS ISLAS FILIPINAS EN LA PRIMERA MITAD DEL SIGLO XVIII
}

\author{
POR \\ M. ${ }^{\text {a }}$ DEL VALLE ALVAREZ MAESTRE \\ Escuela de Estudios Hispanoamericanos \\ CSIC. Sevilla
}

La guerra de Sucesión a la Corona de España, que se produce tras la muerte de Carlos II, dificultó el comercio oficial transatlántico. Terminada ésta y con el cese casi total de las hostilidades en Europa, sería lógico pensar en el restablecimiento de las comunicaciones, y la reorganización y reactivación del comercio de la metrópoli con América. Sin embargo, el estallido de la guerra de la Cuádruple Alianza (1718-1720) hizo que Felipe V utilizase todos los barcos disponibles, de guerra y mercantes, en resolver tales conflictos, de modo, que hasta 1720 , no se toman medidas para atajar la decadencia de régimen de flotas y galeones.

Entre tanto, el verdadero dueño del comercio americano fue el navío de permiso inglés. A pesar de ser los franceses los que tuvieron el asiento de negros desde 1701 a 1713 no supieron aprovechar la posibilidad del comercio ilegal en América, al amparo de la trata de esclavos, en parte porque sus productos tenían suficiente salida en el Pacífico, al margen de las posesiones españolas. Por el contrario, Inglaterra vio en este negocio, de por si apetecible, la forma más eficaz de vender sus manufacturas en el imperio español. Además, en esta época, se estaba desarrollando un floreciente comercio con Extremo Oriente, donde era muy apreciada la plata. Con ella se adquirían sedas, especias y otros productos, obteniendo de su venta en Europa y América un beneficio neto del $60 \%$. Por tanto, el objetivo británico en Indias, no sólo era encontrar mercado para sus manufacturas, sino también conseguir crecidas cantidades de metales preciosos con los que mantener su comercio con Extremo Oriente (1).

SigLA UTILIZADA:

AGI: Archivo General de Indias, Sevilla.

(1) Geoffrey J. WAL.Ker, Política española y comercio colonial, 1700-1789. Barcelona, 1979, págs. 96-97. 
Este hecho, influyó para que a la hora de decidir las normas a seguir en la reorganización de la Carrera de Indias, se optase por aplicar una política proteccionista. Con ello, se crearía una barrera para los extranjeros y se beneficiarían la agricultura y las industrias nacionales.

Indudablemente, el nombramiento de José Patiño para la recién creada Intendencia General de Marina, el 28 de enero de 1717, tuvo especial significado para la reestructuración del comercio indiano. Cuatro meses después de tomar posesión del cargo, se trasladaba definitivamente la Casa de la Contratación a Cádiz, venciendo la oposición de los comerciantes sevillanos. Se le quitaba al Consejo de Indias todo papel en la organización de las flotas y el comercio entre Cádiz y las Indias, pasando toda la responsabilidad a la Corona y a la Casa de la Contratación, centralizándose el control global en manos del nuevo Intendente General de Marina (2). Además, se establecía un servicio regular de buques correo entre España y las colonias, con el que se podría planificar el cargamento de las flotas y galeones a fin de obtener el máximo beneficio de su comercio, empezando a practicarse en 1720 el «Reglamento para Flotas y Galeones».

Sin embargo, el crecimiento del tráfico entre España y el Lejano Oriente, era sumamente perjudicial para el comercio de la flota, cuyo principal cargamento era paño europeo, que no podía competir con las sedas y algodones de China. Las protestas de los comerciantes metropolitanos fueron contundentes. Acusaban a los novohispanos de haber establecido numerosas fábricas de tejidos en China, y como consecuencia, del descenso en los precios de los artículos que transportaba el galeón (3) de modo que

Las gentes de las Américas no gastan ni visten otros géneros, aunque sean de más duración y sustancia, como los de nuestra España, que no pueden darse por los precios de aquellos, ... por lo que el comercio de nuestra España, se halla aniquilado... los géneros de nuestras flotas no hallan salida, si no es con conocida pérdida, ... los derechos de Vuestra Majestad en la mayor miseria, y los comunes intereses de estos súbditos, en la deplorable ruina que experimentan (4).

(2) Ibidem, págs. 135-136.

(3) "Memorial que presenta al Rey nuestro señor, el Tribunal del Consulado y Comercio de Andalucia, y en su nombre don Pedro Ibáñez Aguero, ... sobre que Su Majestad se digne mandar llevar a entero y debido efecto la real cédula, que expidió el 27de octubre de 1720"... AGI. Consulado 61, puntos 18-19.

(4) Ibídem, punto 20. 
1. El Fin del COMERCiO con tejidos ChinOs. LA REAL CÉdula de 27 DE OCTUBRE DE 1720

La real cédula de 27 de octubre de 1720 puso fin al comercio de paños y sedas orientales, limitando la carga del galeón de Manila a porcelana, cera, pimienta, canela y otros artículos que no se producían en España. La cuantía del permiso, sería de 300.000 pesos de principal y 600.000 de retorno, haciéndose la regulación del permiso de carga, por las facturas de los géneros a comerciar (5). Con esto, se intentaba recuperar en parte, los mercados mexicanos para las flotas procedentes de Cádiz. Asimismo se establecía en la cédula que tanto para la conducción del situado como para el comercio con Acapulco, se emplearan dos navíos de 500 toneladas cada uno, y no uno solo como hasta entonces en atención a lo dilatado del viaje, y a lo que ocupan los bastimentos y pertrechos necesarios (6).

Para evitar el retraso en el cumplimiento de esta cédula se ordena ejecutarla en los primeros navíos, que tras su publicación en Filipinas salieran para hacer la carrera. Sólo después de cumplirla, el gobernador de Filipinas y las demás autoridades podrían reclamar. En caso contrario, se les privaría de sus bienes y oficios, y desterraría perpetuamente de las Indias (7). El resto del articulado de esta real cédula, lo hemos clasificado en tres grandes apartados, para su mejor comprensión y comparación con otras posteriores: buque, carga y derechos, que pormenorizadamente se analizan a continuación.

\subsection{Distribución del buque}

La numeración para el reparto del buque, entre aquellos que tenían derecho al comercio con Nueva España - vecinos de Manila y españoles de cualquier profesión residentes en Cavite-, la haría la Ciudad de Manila, sin la intervención de ninguna otra

(5) Antonio Joseph Alvarez. DE ABReu, Extracto Historial del expediente que pende en el Consejo Real y Supremo de las Indias, a instancia de la Ciudad de Manila, y demás de las Islas Philipinas, sobre la forma en que se ha de hacer y continuar el comercio, y la contratación de los tejidos de China en Nueva España: $Y$ para la mejor comprehensión, distinguiendo y separando Tiempos, se notan los lances de esta dependencia, desde el descubrimiento de las Islas Philipinas, y la concesion de su comercio, con todo lo que ha ocurrido hasta el presente de oficio, y a instancias del Consulado y comercio de España. Madrid, 1736, fols. 41-42.

(6) Ibidem, fols. 41 vto.-42.

(7) Ibidem, fol. 41 vto. 
autoridad civil. Una vez confeccionada la lista, se presentaría a una Junta, encargada de distribuir las toneladas hábiles para el comercio que quedasen en las naos. La Junta tendría en cuenta a la hora del reparto, la prohibición de participar en él al clero regular o secular, ministros, forasteros y oficiales de las naves, aunque se permite a los soldados y marineros de la tripulación, embarcar con su ropa alguna caja, cuyo contenido no excediera de 30 pesos de valor en Filipinas, sin menoscabo del permiso de 300.000 pesos (8).

La Junta debía recuperar todas las boletas de aquellos que no pudieran utilizarlas personalmente, para su posterior redistribución entre todos los comerciantes, ya que se anulaba la posibilidad de ceder su derecho a otro.

Con esta legislación se permitía a los interesados recurrir a la Junta, si se sintieran agraviados en la numeración, para que en el repartimiento se les compensara y a la Audiencia, si el perjuicio proviniera de la Junta (9). Una vez concluido el proceso de repartimiento, los comerciantes harían juramento formal de que era de su propiedad todo lo que enviaban a Nueva España, presentando en el plazo que se les señalara las facturas de los géneros que iban a embarcar para su valoración. A esta, asistirán dos peritos, diputados de la ciudad y comercio, con los oficiales reales y el fiscal de la Audiencia de Manila, quien supervisaría todo el avalúo (10) $\mathrm{Si}$ el valor de la carga excediera de los 300.000 pesos, se la reduciría hasta alcanzar lo permitido. En caso contrario, se podría completar esa cantidad. No obstante, se advierte que cuanto menos cargada fuese la nave más seguridad tendría, más comodidad para los pasajeros, aumentándose las ganancias de las mercancías a la vez que se abreviarían las ferias y se perjudicaría menos al Comercio de España (11).

\subsection{Procedimientos para la carga de mercancías en Cavite $y$ formalidades para su descarga en Acapulco}

Responsables para impedir el contrabando seguirían siendo los oficiales reales, el fiscal y los maestres de las naos. Así los oficiales y el fiscal, abrirían algunos fardos al azar, para comprobar si existía fraude y castigarlo, debiendo asistir al embarque de

(8) Ibidem, fols. 42 vto. -43 vto.

(9) Ibidem, fols. $42-42$ vto.

(10) Ibidem, fol. 42 vto.

(11) Ibidem, fols. 42 vto.-43. 
las mercancías y tras apuntar en un registro todo el cargamento, visitarían las naves entregando al maestre de cada nao su registro, en el que constaría el testimonio de esta real cédula, la numeración de comerciantes, el repartimiento otorgado por la Junta, el inventario de los géneros, su precio y el nombre sus dueños así como el juramento de que los comercian por cuenta propia (12).

El maestre de cada nao, formaría por duplicado, un libro de sobordo, que presentaría para la descarga al castellano y oficiales reales de Acapulco. Un ejemplar se remitiría al virrey para que lo legalizara y lo mande al tribunal de cuentas de México, donde se copiará, mandándose el original al Consejo de Indias (13).

Si en Cavite era necesario el control, en Acapulco era imprescindible. No podemos olvidar que en su recorrido de Manila a San Bernardino el galeón pasaba por numerosos enclaves donde se podía cargar con contrabando. Además, una vez atracado en Acapulco, podía sufrir robos, o simplemente, los propios interesados ante la falta de vigilancia, sacar los bultos que iban fuera de registro (14). Se ordenaba por tanto al castellano-gobernador y oficiales reales de Acapulco, poner la guardia suficiente para evitar "ocultaciones y furtivas introducciones", asistir al desembarco de la carga y cobrar los derechos establecidos, pero sin entorpecer la descarga para no perjudicar a los comerciantes con las demoras. Una vez sacado y examinado lo que iba en el registro se inspeccionarían los bajeles, decomisando todo lo demás que encontrasen, sin dar lugar a reclamaciones, ya que en adelante, quedaban totalmente prohibidas las «manifestaciones». El Rey, para atajar de raíz el fraude renunciaba al cobro de los derechos doblados. Al mismo tiempo, para estimular las denuncias se estipulaba el reparto del decomiso. La mitad de su valor, iría a la Real Hacienda y la otra mitad, a repartir por igual entre el juez y el denunciante, siempre que lo requisado no superase los 50.000 pesos; si así fuese, el virrey y el real acuerdo, les señalarán la parte que les pareciera proporcionada. Si el decomiso se pro-

(12) Ibidem, fol. 43.

(13) Ibidem, fol. 43.

(14) La organizada red para la introducción en el galeón de mercancías fuera de registro y la dificultad de navegación entre islas y escollos, hicieron que diez años más tarde el entonces gobernador de Filipinas Fernando Valdés Tamón (1729-1739), intentase aunque sin éxito, poner en práctica el proyecto del piloto Enrique Herman para hacer el derrotero por la ruta del cabo Engaño. Este tema ha sido estudiado por M. ${ }^{\text {a }}$ Lourdes Díaz-Trechuelo, "Dos nuevos derroteros del galeón de Manila (1730 y 1773)". Anuario de Estudios Americanos. Sevilla, 1956, tomo XIII, págs. 1-83. 
dujera en Filipinas, recaería sobre la audiencia la responsabilidad del reparto y del castigo a los infractores.

Y para que nadie alegara ignorancia se publicaba un bahdo con estas órdenes en Manila, México y Acapulco (15).

\subsection{Derechos a pagar por el Comercio de Manila y reglas para el retorno a las Islas}

Se establece un tanto alzado (100.000 pesos) en concepto de todos los impuestos que tuvieran que pagarse, tanto a la ida como a la vuelta; tampoco se pagaría alcabala de la primera venta, aunque sí de las sucesivas. Esta contribución, representaría aproximadamente, un $17 \%$ del retorno permitido. Se estimaba que el $83 \%$ restante era suficiente ganancia, sobre todo teniendo en cuenta que la Real Hacienda costeaba las fábricas, carenas, aprestos, sueldos de la tripulación, víveres, pertrechos y municiones de los bajeles, cobrando sólo 44 ducados por tonelada de repartimiento.

En cualquier caso, la cédula no da opción a reclamaciones en este sentido. Concluye este apartado con un ultimatum: $\mathrm{O}$ la ciudad y comercio de Manila aceptan la nueva regulación, o se le exigirá el pago de todos los derechos (16).

En ningún caso, el retorno de los beneficios de los comerciantes filipinos podría superar los 600.000 pesos. Para el caso de que la feria fuese tan ventajosa que se sobrepasara esa cifra, se preveía la posibilidad de embarcar los 600.000 pesos en reales y el excedente en frutos y géneros de Nueva España, pagando los derechos acostumbrados.

Para evitar el fraude, se obligaba a los comerciantes que vinieran de Filipinas y a los factores y apoderados de los que no vinieran, a sacar unas licencias para embarcar el dinero. El virrey debía vigilar que su expedición fuese rápida y gratuita, tanto para los mercaderes que vendieran su género en el interior, como para los que lo hicieran en Acapulco. A estos últimos, se las extenderían los oficiales reales y el castellano del puerto.

El paso siguiente, sería el reconocimiento de estas licencias que habrian de presentarse previamente al embarco. Si la plata que se pretendía cargar, sobrepasara los 600.000 pesos, se prorratearía el exceso entre todos, según las toneladas que se le

(15) Alvarez de Abreu, [5], fols. 43-43 vto.

(16) Ibidem, fols. 44 vto.-45. 
repartieron y los avalúos hechos en Filipinas, que para este efecto, debían estar en poder del castellano y oficiales reales de Acapulco. $\mathrm{Si}$ por el contrario, el producto de las ventas no llegase a los 600.000 pesos, se prohíbe que el virrey o cualquier otra autoridad, de permiso bajo ningún pretexto, por justificado que pareciera, para enviar desde México lo que faltase, por saberse, que de esta forma, se han ido infiltrando en el comercio de Filipinas los naturales y residentes de Nueva España, causando gravísimos problemas al real erario y al comercio metropolitano. En definitiva, se hace hincapié en la exclusiva participación de los filipinos en el comercio del galeón.

Para cumplir este objetivo, se estipulan una serie de castigos y recompensas para los infractores y denunciantes. Se amenaza a los jueces isleños y novohispanos con graves penas si no desempeñaran su cargo conforme a esta disposición. Si se descubriera un fraude se decomisaría de inmediato, cobrando el juez y el denunciante la parte que les correspondiera. El delincuente pagaría a la real hacienda el $3 \%$ de lo decomisado si era la primera vez; en caso de reincidencia, se castigaría con la pérdida de sus bienes y el destierro por diez años de las provincias del virreinato (17).

La ruina que para la economía isleña supuso la prohibición del tráfico de tejidos chinos, queda plasmada en la carta, que años después y recordando esta situación, escribieron al rey los diputados del Comercio de Manila. En ella explican que en esta época se deterioró tanto el comercio, que para no llegar a la quiebra total, en 1725 se deliberó enviar solo un patache en lastre para conducir el situado (18).

\subsection{El derecho de palmeo}

Esta medida, ya "per se», perjudicial para los comerciantes y vecinos de Manila, se vio agravada por el llamado Proyecto de 1720. En él Felipe V trató de modificar el régimen aduanero, eliminando varias gabelas y contribuciones extraordinarias, consideradas costosas para los comercios de España y América. Sin embargo, el nuevo arancel puesto en vigor a partir de abril de 1720 , no sólo no introdujo reformas sustanciales, sino que algunas

(17) Ibidem, fols. 43 vto.-44.

(18) Carta de la ciudad de Manila y diputados de su comercio al Rey. Sala Capitular. Manila 10 octubre 1732. AGI. Filipinas, 420. 
de sus innovaciones fueron poco afortunadas. A saber: Para un determinado número de efectos se eliminó el antiguo sistema que hacía recaer el impuesto sobre el valor de la mercancía. En lo sucesivo, se tasaría en función del peso; otro grupo, continuó pagando derechos «ad valorem». Pero la principal novedad del decreto fue el impuesto por el volumen (midiéndose éste por palmos) con el que se gravó la mayoría de los artículos (19).

Las consecuencias del llamado derecho de palmeo, fueron particularmente nefastas para el comercio filipino, puesto que por la citada real cédula se le prohibió todo tráfico de paños finos y sedas, y por otra parte el comercio de tejidos gruesos y voluminosos no era rentable.

Años más tarde. Campillo criticó duramente este impuesto, haciéndolo responsable de la decadencia del comercio español, por alentar a que se excluyeran de él las mercancías de mucho volumen y poco valor; ya que se pagaba lo mismo por un palmo con valor de 2 pesos, que por el de 20 (20).

Las autoridades de Manila ejercieron ante la Corona todas las presiones a su alcance para obtener un nuevo permiso de tráfico de seda. Diputados de Manila llegaron a la Corte argumentando sus necesidades, consideradas por el Consulado andaluz ficticias y fraudulentas (21).

\section{UN RESPIRO PARA EL COMERCIO DE LAS ISLAS: EL REGLAMENTO DE 21 DE OCTUBRE DE 1726}

El resultado de estas gestiones, fue favorable para los vecinos de Manila, ya que la prohibición del comercio de seda, fue derogada cuatro años más tarde (17 de junio de 1724). Sin embargo, esto no era suficiente para la maltrecha situación económica de las Islas, y a pesar de que el Comercio de España, presentó en 1725 un memorial al rey indicándole la ruina que

(19) Eduardo Arcila Farias: Reformas económicas del siglo XVIII en Nueva España. I. Ideas económicas, comercio y régimen de comercio libre. México, 1974, págs. 126-128.

(20) Ibídem, pág. 128.

(21) "Respóndese a los argumentos y reparos por los diputados de la Ciudad de Manila, sobre la proposición hecha por el comercio de España al de las islas Filipinas, para que pueda traficar toda la canela, pimienta y clavo que necesite el reyno de Nueva España, en lugar y por equivalente de los tejidos y ropas de seda de China... sin la inclusión de los expresados tejidos de China, tienen sobrados géneros con los que llenar su permiso... Como se les demuestra". AGI Consulado, 61. fol. 4. 
esta nueva orden traería al tráfico e industria sedera de la Península (22), se otorgó la real cédula de 15 de septiembre de 1728 por la que el galeón podría transportar mercancías por valor de 300.000 pesos y retornar 600.000 , la cual fue superada un mes más tarde por el Reglamento de 21 de octubre del mismo año, por el que durante un quinquenio, se abrian las puertas al comercio de las sederías chinas en Acapulco. El Galeón, podría transportar 4.000 piezas, que le haría retornar 1.200 .000 pesos.

Este giro en la política comercial de Patiño, se debió a que precisamente a partir de 1726, comenzaba a ser evidente el fracaso de los comerciantes andaluces para mantener el monopolio y aumentar el comercio con las Indias. «El cambio, no obedeció a ningún deseo de favorecer específicamente a los comerciantes coloniales, sino que fue una simple cuestión de pragmatismo en una esfera en la que los galeones y la flota estaban demostrando su gran ineptitud» (23). En 1729 la Ciudad y Comercio de Manila empezaron a disfrutar el permiso por el que podían enviar 4.000 piezas a Nueva España; de ellas, 500 serían medios cajones para albergar sedas y ropas muy finas y 3.500 medios fardillos, churlos (24) de canela, balsas de loza y marquetas (25) de cera (26). Tanto los medios cajones como los medios fardillos debían medir vara y cuarta de largo, dos tercias de ancho y una tercia de alto. Sobre estas medidas se les admitiría al descargar en Acapulco, un exceso de dos dedos, por lo que ocuparan los abrigos de estera y de encerada gruesa doblada (27).

Los churlos de canela debían pesar en Filipinas 150 libras, incluidos los abrigos y encerados, aunque en Acapulco se permitiría cuatro o cinco libras de más. Esta misma diferencia se aplicaría en México a las marquetas de cera, que saldrían de Cavite con 12 arrobas. Las balsas de loza, serían de una vara de alto por dos varas y cuarta de circunferencia en la boca (28).

Para dar agilidad a la descarga, se exige a la Ciudad y Comercio de Manila hacer estas medidas en bronce, distinguiendo el aumento de los dos dedos, y tras sellarlas con sus armas, enviarlas

(22) Vid. nota 3.

(23) WALKER [1], pág. 203-204.

(24) Churlo: Saco de lienzo de pita cubierto con uno de cuero.

(25) Marquetas: Pan o porción de cera sin labrar.

(26) "Testimonio de los autos sobre medidas en que deba arreglarse la Ciudad y Comercio de Manila en el envio de sus fardos". Madrid 2 noviembre 1726. AGI Filipinas, 430. art. 1.

(27) Ibidem, arts. 2 y 3.

(28) Ibidem, arts. 4, 6 y 5. 
al castellano y oficiales reales de Acapulco con ellas se comprobaría rápidamente si había exceso (29).

Para embarcar cajones grandes con escritorios o biombos, había que regular las piezas de buque que ocupara cada cajón, para no superar las 4.000 piezas fijadas ni disminuir los 500 medios cajones que se piden (30). Sin embargo, con estoraque (31) y pimienta se podía traficar libremente, al margen de las 4.000 piezas (32).

Para conducir estas mercancías se preveía la construcción de galeones de 60 codos de quilla, 20 de manga y 10 de puntal. Contarían con una tripulación de 250 hombres, excluidos los oficiales a quienes elegiría el gobernador, siendo los contramaestres los responsables de lastrar los navíos, recibir los pertrechos y arrumar la carga (33).

\subsection{Distribución del buque}

La numeración para el reparto del buque la realizaría a partir de ahora una Junta de Repartimiento, compuesta por el oidor decano o ministro que lo siga en antigüedad, el fiscal, el arzobispo o el deán, un alcalde ordinario, un regidor y un compromisario de los ocho que componen el comercio, dando en estos tres últimos casos prioridad a los más antiguos (34). La lista que resulte se expondrá en el Ayuntamiento (35), firmada por todos los miembros de la Junta y refrendada por el escribano ante el cual se hizo. Ante posibles pleitos con esta fórmula sólo se daba opción de recurrir a la Audiencia, excluidos los ministros que participaron en el reparto. El referido escribano mandaría copia manuscrita y sin enmienda, igualmente firmada por los componentes de la Junta, a su homónimo de registros, para que la ponga encabezando el que se manda a Nueva España (36).

La Junta, sin embargo, debía respetar las asignaciones previamente establecidas a la hora de distribuir el espacio para carga.

(29) Ibidem, art. 11.

(30) Ibidem, art. 8.

(31) Estoraque: Arbol estiracáceo de flores blancas y fruto elipsoidal, de cuyo tronco se obtiene un bálsamo muy oloroso.

(32) Ibidem, art. 7.

(33) Ibidem, arts. 13, 14 y 15.

(34) Ibidem, arts. 16 y 17.

(35) Antes se fijaba a la entrada del palacio del gobernador.

(36) Ibidem, arts. 18 y 19. 
Así, el gobernador, los ministros togados y los oficiales reales de Manila, tenían derecho a 100 piezas de las 4.000 permitidas para poder enviar cajones con regalos, bien entendido que estos cajones no se incluirían en el número de 500 pedidos para el comercio y los oficiales de las naos a 200 piezas, distribuidas en función del puesto: 50 para el general, 30 para el piloto mayor, al segundo piloto y al contramaestre le correspondían 25 piezas a cada uno, al tercer piloto 20 , al guardián 15 , igual que al condestable, 8 al despensero, 6 al buzo y otras tantas al alguacil (37).

Para los miembros de la tripulación, se preveía la posibilidad de embarcar una caja de mayor o menor volumen, según su empleo. La de cada artillero sería de vara y cuarta de largo por dos de alto y dos tercios de ancho. Las de los marineros, medirían vara y cuatro dedos de largo por media de alto y de ancho. Los grumetes españoles, la llevarían de una vara de largo media de ancho y media de alto mientras que los grumetes sencillos, no tenían derecho a embarcar nada (38).

Los pasajeros, tenía que jurar «a priori» que entre sus ropas no iba mercancía prohibida, pues expresamente y bajo pena de decomiso en Acapulco, se les niega el comercio, aunqué para llevar sus ropas, se les permiten dos cajas o petacas a cada uno (39). En el reparto, también debía incluirse el cabildo eclesiástico de Manila, que accedería a él por vía de limosna, y a las viudas de comerciantes y militares, según sus caudales y servicios (40).

Se prohibe dar parte en la carga a familiares del gobernador y ministros togados que no estén casados en las Islas, así como enviar a México cajas de regalo que no están incluidas en las 4.000 piezas, o llevar la ropa en tinajas, loza o cera (41).

Sin embargo, se autoriza la cesión a otra persona de la parte del buque que no se utilice, con la sóla obligación de que ésta pertenezca a la lista de comerciantes, dejando el que la cede constancia firmada en la boleta de su renuncia (42). Esta cesión supuso un buen negocio para los grandes comerciantes que paulatinamente se fueron haciendo con el monopolio comercial.

(37) Ibidem, arts. 20 y 22.

(38) Ibidem, art. 36.

(39) Ibidem, arts. 26 y 10.

(40) Ibidem, arts. 21 y 23.

(41) Ibidem, arts. 24, 43 y 9.

(42) Ibidem, art. 25. 


\subsection{Procedimiento para la carga de mercancías en Cavite y formalidades para su descarga en Acapulco}

Se establecen una serie de responsabilidades en cadena, adscritas a diferentes miembros de la administración, del comercio y oficialidad de la nao. Probablemente este sistema de control escalonado, vaya encaminado a evitar sobornos (43). El primer peldaño lo ocupa el escribano de registros, quien previamente ha recibido los despachos dados en la contaduría de Manila, para la carga de los navíos. Responsables de los excesos de medidas en Acapulco serán, el maestre, el fiscal, el regidor y el compromisario más antiguos, que deberán asistir a la carga del barco e informar a los interventores. Estos inspeccionarán los bajeles y entregarán el registro al maestre de nao. Encabezándolo, estará la lista del repartimiento del buque.

Por último, el maestre formará un libro de sobordo a medida que se vayan cargando las mercancías, que presentará al castellano gobernador y oficiales reales de Acapulco, para que comprueben en la descarga si todo está conforme a registro. En caso contrario, se procederá contra el maestre del galeón.

Se ordena al castellano-gobernador y oficiales reales de Acapulco velar para impedir el fraude, pero a su vez, se insiste en que ni ellos, ni cualquier otra autoridad, entorpezcan la labor de los mercaderes, ni apremiarlos a vender sus mercancías en la feria o fuera de ella; sólo exigirán los impuestos. Para cuidar los intereses del comercio peninsular, el Consulado de Cádiz tenía derecho a que uno de sus diputados estuviese presente en la descarga del navío. Igualmente se dispone la asistencia al desembarco de los diputados del Comercio de Filipinas, para confirmar los excesos en las medidas si los hubiera. Ásí se pretende evitar los conflictos surgidos por la opinión unilateral de los oficiales reales de México; a su vez, los diputados isleños podían designar personas de su confianza, como guardianes de la carga para impedir robos (44).

Una vez desembarcado y examinado lo que va en el registro se decomisará el resto de mercancías encontradas y luego, se remitirá al Consejo de Indias un informe de la descarga, firmado por el castellano, oficiales reales de Acapulco y diputados del Comercio de Filipinas que participaron; en él, vendrán anotados individualmente los excesos encontrados en las medidas y pesos

(43) Ibidem, arts. 27, 28, 29 y 30.

(44) Ibidem, arts. 31, 35, 42, 11 y 32. 
y los números y marcas de las piezas que los rebasan así como los nombres de sus dueños (45).

\subsection{Derechos a pagar por el Comercio de Manila y reglas para el retorno a las Islas}

Al margen de toda eventualidad, el Comercio de Manila tenía que pagar 25.000 pesos por cada navío que llegase a Acapulco (46), lo que desató numerosas quejas en las islas.

Del producto de la venta de las 4.000 piezas, el real erario recaudaba el $5 \%$ de almojarifazgo, igual que en Cádiz pagaba el Comercio de España. Además, existían contribuciones específicas: Por cada medio cajón, se cobraba 45 pesos, 30 por cada medio fardillo, 25 pesos por los churlos de canela, 18 por las marquetas de cera, igual que por los escritorios y biombos y 12 reales de plata por cada arroba de pimienta y estoraque. En cambio, no se pagaría alcabala de la primera venta aunque sí de las posteriores. Además, se permite a quienes hayan tenido que quedarse con mercancías de un año para otro, embarcar los beneficios devengados por ellas, en el siguiente galeón (47).

Uno de los principales reproches que sobre el comercio del galeón hacia el consulado gaditano, era que los vecinos y residentes en México, a quienes por ley les estaba vedado el comercio, utilizaban como testaferros a los filipinos para enviar al archipiélago frutos y géneros mexicanos para traficar con ellos y plata que invertirían en mercancías, normalmente seda china, llevadas a Acapulco por el galeón al año siguiente. Para impedirlo, se dispone que todo mercader filipino que quisiera embarcar plata, hará juramento formal ante el castellano-gobernador y oficiales reales del puerto, de que no pertenece a residentes 0 vecinos novohispanos.

Estos juramentos constarán en los registros, debiendo el gobernador de Manila comprobar la propiedad de la plata a la llegada de los galeones. El fraude se castigaría con la pérdida de la cantidad, más el $3 \%$ de multa y destierro perpetuo de las islas, si el portador fuese soltero; si era casado, con la exclusión perpetua del repartimiento. El mismo juramento se hará para embarcar géneros o frutos de Nueva España, además de pagar los derechos

(45) Ibidem, arts. 34 y 33.

(46) Ibidem, art. 44.

(47) Ibidem, arts. 46 y 37. 
acostumbrados, exceptuando los comestibles por ser necesarios para la alimentación en el viaje, y los regalos para Manila (48).

Contrastando con las duras penas impuestas a los transgresores están las facilidades que en teoría, se daban a los comerciantes isleños para regresar con sus ganancias a Manila. No sólo se permite el embarque del valor generado por la venta de las 4.000 piezas, sino que se posibilita a los comerciates filipinos, el retorno de las ganancias retenidas en Nueva España aunque superaran los 600.000 pesos, cantidad que hasta 1729 , e independientemente de lo ganado en México, era la única que legalmente se podía reintegrar al archipiélago. Los requisitos previos exigidos para acogerse a esta nueva medida eran: el pago del $10 \%$ del dinero embarcado y'la justificación formal ante el virrey de ser vecinos de Manila y tener tales cantidades bloqueadas por falta de permiso (49).

Estas medidas dieron un respiro a la economía de Filipinas, pero pronto se reemprendió el acoso, nunca cesado del todo, por parte del comercio español, esta vez apoyados por el virrey de México marqués de Casafuerte. El virrey, tras informar sobre el fraude por exceso de géneros y caudal del galeón Nuestra Señora de Guía (50) recibe la real orden de 1 de agosto de 1731 por la que se le mandaba dar una reglamentación para el tráfico de las Islas con Nueva España (51).

\section{UNA NUEVA LIMITACIÓN PARA EL COMERCIO SEDERO: LA REAL CÉDULA DE 8 DE ABRIL DE 1734}

En virtud de esta orden, y cuando en Manila se confiaba en la prórroga del quinquenio, o al menos en el permiso para acogerse a la real cédula de 17 de junio de 1724. Los pataches que en 1732 llegaron de Nueva España, llevaron la noticia de que a partir de 1734, entraría en vigor la cédula dada en Balsaín el 27 de octubre de 1720, que prohibía expresamente el comercio con

(48) Ibidem, arts. 39, 41 y 40.

(49) Ibidem, arts. 38 y 45.

(50) Ibidem, "Respóndese a los argumentos y reparos por los diputados de la Ciudad de Manila, sobre la proposición hecha por el comercio de España al de las islas Filipinas, para que pueda traficar toda la canela, pimienta y clavo que necesite el reyno de Nueva España, en lugar y por equivalente de los tejidos y ropas de seda de China..." AGI. Consulado 61, fol. 4 vto.

(51) "Real cédula dada en El Buen Retiro el 8 abril 1734 a D. Juan Antonio de Vizarrón y Eguiarreta, ... Arzobispo de la Santa Iglesia Catedral Metropolitana de México, Virrey de Nueva España, ..." AGI. Filipinas 120, fol. 2. 
seda china. Esta noticia, alarmó e indignó a los diputados del comercio de Manila, quienes comunicaron al Rey la ruina que se les avecinaba (52). En cuanto a los agravios alegados por los comerciantes españoles, afirmaban que eran falacias. Según los informes "de los ministros y prelados superiores de las islas, y de los testigos extranjeros a quienes les está permitido el comercion (53) la realidad, era que desde hacia algunos años arribaban a Cantón entre 12 y 18 mercantes europeos, con más de 4.000 .000 de pesos de plata con cuños mexicanos y peruanos, que invertían en tejidos y sedas. Por esto, y porque estas mercancías no eran adecuadas para sus reinos por la calidad del género y la climatología de sus países, era fácil deducir, que las adquirían para ser vendidas en ambos virreinatos.

Concluyen exponiendo, que en cualquier caso, 500 cajones de permiso anual, aunque todos fueran de tejido, "que nunca han llegado" (54) no podrán saturar el mercado de Nueva España como para que se abandonaran los europeos o disminuya su valor. En definitiva, que era mucho menos perjudicial 500 cajones, que los 4.000 .000 de pesos reducidos a mercancías de seda que introducían los forasteros por el comercio de España en América. Así, se quiere quitar a Filipinas las ganancias que emplea en el mantenimiento y evangelización de las islas, para dárselas a los extranjeros, potenciales enemigos de España (55).

Treinta y siete años más tarde esta tesis es sustentada por el contador Tomás Ortiz de Landazuri, quién se plantea si es legítimo que subsista en 1767, el recelo que el comercio con China suscitó en tiempos de Felipe II. La conclusión a la que llega, es que si la prohibición del comercio, va a favorecer a los extranjeros, convendrá anularla y alentar el tráfico de los propios vasallos del Rey (56).

Para hacer hincapié en sus deseos, los diputados de la ciudad y comercio de Manila, junto con el sargento mayor don Lorenzo Rugama y Palacio, y don Miguel Fernández Munilla, secretario del Consejo de Castilla, hicieron un informe al Rey (57) en el

(52) Carta de la ciudad de Manila y diputados de su comercio al Rey. Sala Capitular. Manila 10 oct. 1732. AGI Filipinas 420.

(53) Ibidem.

(54) Ibidem.

(55) Ibidem.

(56) Luis Navarro García, "El comercio interamericano por la mar del Sur en la Edad Moderna". Revista de Historia. IV, no 23. Caracas, mayo 1965, págs. $39-40$ y 44.

(57) Mencionada en los preliminares de la real cédula de 8 abril 1734. AGI Filipinas 120, fol. 1. 
mantienen que para la conservación y propagación de la fe católica, obras pías y manutención de los naturales era imprescindible el comercio con Nueva España que permitiese el retorno de 1.200 .000 pesos, y el envío de su principal correspondiente, lo que sería imposible, si se prohibía el tráfico de seda y ropa china. Tras esta exposición, pasan a hacer una serie de peticiones:

1. Que a pesar de lo ordenado por el virrey, se conceda para siempre al comercio de Filipinas licencia y facultad, para que "con imposición de perpetuo silencio al de Andalucía y Consulado de Cádiz» (58) cada galeón pudiera conducir las 4.000 piezas aprobadas por el reglamento de 1726, con el retorno libre de su producto, al menos hasta la cantidad de 1.200 .000 pesos.

2. Anulación de las órdenes del virrey, por ser contrarias a la real cédula de 17 de junio de 1724, de modo que si por cualquier circunstancia, las ganancias de la feria excedieran de 1.200.000 pesos, el Comercio de Manila, sólo tendría que contribuir con el $5 \%$ del aumento, excluidos los efectos que se llevasen de Nueva España para el gasto personal (jabón, cajas de dulces, frutos, etc.).

3. Que las marquetas de cera, pudiesen pesar 18 arrobas netas, por haberse comprobado que con sólo 12 no producían beneficios, pero ésto, sin aumentar los impuestos.

4. Liberación para el comercio de Manila de los 20.000 pesos anuales de contribución para la concesión del quinquenio, atendiendo a que con la regulación de derechos por cada pieza, y el $5 \%$ de lo que se embarcaba, la real hacienda obtenía una renta notable.

5. Que si por cualquier circunstancia algún año no llegase el galeón a Acapulco o fuese en lastre, pudieran los interesados compensarse al año siguiente, retornando toda la plata, aunque superase 1.200 .000 pesos, sin pagar más impuestos que el $5 \%$ del exceso.

6. Por último, en el caso de que estas peticiones no fuesen aceptadas exigían la prórroga, al menos durante otro quinquenio, del permiso de 1726, aunque anulando la contribución de 20.000 pesos anuales, antes mencionados.

El Rey tras consultas del Consejo en 19 y 23 de diciembre de 1733, daba un nuevo reglamento para el comercio de Filipinas

(58) Ibidem. 
con Nueva España. Nace así la real cédula dada en el Buen Retiro el 8 de abril de 1734 (59). Con ella se revocaba la de 27 de octubre de 1720, que prohibía el comercio de la seda, y las órdenes del virrey sobre que una vez terminado el quinquenio de permisión, el galeón que partiese de Filipinas en 1734, se ajustase a la antedicha cédula de 1720 (60).

Se establecía por el contrario, que cada año en la nao que fuese a Acapulco por el situado, pudieran enviarse 500.000 pesos de principal en tejidos y ropas, tanto de factura isleña como de seda china, además de frutos y otros productos hasta entonces permitidos. El valor que se concede al retorno es de 1.000 .000 de pesos anuales. Se cambia el modo de regular el permiso de la carga: ya no se hará por piezas ni se abrirán los fardos y cajones para evaluar la carga, sino por facturas, que cada cual ha de presentar en la contaduría de Manila en el término asignado, con juramento solemne de ser suyas todas las mercancías reflejadas en ellas, y de no embarcar más de lo expresado (61). No se cambian las medidas de fardos, cajones etc. que serán las utilizadas hasta la fecha, siempre que no superen, con el aumento de la cuarta parte de extensión que se les permitió por cédulas de 12 de agosto de 1702 y 23 de octubre de 1733. Las marquetas de cera se atendrán al peso y tamaño utilizado antes de 1726 (62).

\subsection{Distribución del buque}

La numeración de comerciantes, la volvería a hacer en solitario la ciudad de Manila, sin la presencia de ningún ministro. En ella, se incluiría a los naturales y españoles que se encuentren en Cavite y no les esté vedado el comercio. La lista que resulte, se presentaría a la Junta de Repartimiento, compuesta por el gobernador de Filipinas, el oidor decano o el que le siguiera en antigüedad, el arzobispo y en su defecto el deán, un alcalde ordinario de Manila, un regidor y un compromisario. Estos dos últimos, asistirian por riguroso turno anual, lo mismo que los que tengan que asistir al carguío de las naos, a pesar de lo mandado por el despacho de 15 de septiembre de 1726. Es la junta, la que distribuye entre los comerciantes incluidos en la numeración, las

(59) Vid. nota 51, fol. 3. Esta cédula también se encuentra manuscrita en AGI. Filipinas 430.

(60) Ibidem, art. 1.

(61) Ibidem, arts. 2 y 3.

(62) Ibidem, art. 22. 
toneladas que queden útiles del galeón, teniendo presente que se prohíbe expresamente incluir al clero, regular o secular, y a los extranjeros residentes en las islas. Se anula, igualmente, la posibilidad de especular con el espacio de carga, exceptuando a los pobres y viudas. Los que no pudieran usar por sí mismos del repartimiento, tendrian que devolver sus boletas a la junta, para que fuesen redistribuidas sus piezas entre los demás comerciantes (63).

Con esta legislación se da al posible perjudicado opción a recurrir, en primera instancia ante la junta y en segunda a la audiencia, excluidos los ministros que participaron en el repartimiento. En ambos casos, se ordena proceder breve y sumariamente (64).

Concluido el proceso de reparto de boletas los interesados presentarían, en el plano que se les asigne, las facturas de los géneros que iban a enviar, para que se valore lo que importan. A esta valoración asistirían dos peritos diputados de la ciudad y comercio, con los oficiales reales y el fiscal de la audiencia de Manila. De no cubrirse los 500.000 pesos y si el buque admitiera más carga, se concederá permiso para completar la cantidad aunque se advierte de las ventajas que proporciona el llevar menos mercancías. Si por el contrario, el valor de la carga superase los 500.000 pesos, se rebajará el cargamento hasta dejarlo en lo asignado (65). Al margen del permiso, la junta debía reservar espacio para que los soldados y marineros de la tripulación excluidos los oficiales pudiesen embarcar con su ropa alguna caja, cuyo contenido no sobrepasase los 30 pesos de valor en Filipinas (66).

\subsection{Procedimiento para la carga de mercancías en Cavite y formalidades para su descarga en Acapulco}

Evitar los posibles fraudes era la resposabilidad del fiscal, los oficiales reales y el comandante o maestre del galeón. Así los oficiales reales, $\mathrm{o}$ al menos uno de ellos, y el fiscal, tendrían que estar presentes en el embarque de las mercancías y después de registrado todo el cargamento, inspeccionar las naves que iban a

(63) Ibidem, arts. 5, 23 y 6.

(64) Ibidem, art. 8.

(65) Ibidem, arts. 7, 10 y 9.

(66) Ibidem, art. 16. 
partir, entregando el registro al maestre de cada una. En él constaría, en primer lugar, la numeración de comerciantes; luego, el repartimiento otorgado por la junta y, sucesivamente, las facturas y precios de los géneros que la integraban con el nombre de sus dueños y el juramento de que comerciaban por su cuenta (67).

El maestre de cada barco, formaría por duplicado un libro de sobordo, que presentaría para la descarga al castellano y oficiales reales de Acapulco. Otro ejemplar se llevaría al virrey para que lo autentifique y lo mandara al tribunal de cuentas de México, donde se copiaría, enviándose al Consejo de Indias el original de Filipinas (68).

Los responsables principales de la operación de descarga serían el castellano y oficiales reales del puerto, por ser los encargados de recibir los barcos. Se les ordenaba poner guardia para evitar «ocultaciones e introducciones furtivas», y en su presencia, hacer que se descargue el galeón sin tardanza, cobrando la cantidad que a prorrata tenga que abonar el Comercio de Manila, o los derechos establecidos, para que con la demora no se perjudique a los comerciantes (69).

Una vez desembarcadas las mercancías y comprobado lo que iba en el registro, se decomisaría lo demás que se encuentre; y para atajar de raíz el fraude se prohíbe la posibilidad de pagar derechos dobles por lo que exceda del permiso o por lo no registrado. Para contrarrestar los sobornos y estimular la denuncia, lo decomisado se repartiría, la mitad para la real hacienda y la otra mitad se dividiría, en partes iguales, entre el juez y el denunciante, si el importe de lo requisado no superase los 50.000 pesos; si fuese mayor, el virrey y el Real Acuerdo de México señalarían al juez y al denunciante la cantidad que les pareciese justa. Si el comiso se produjera en Filipinas, esta acción correspondería a la audiencia, dejando al arbitrio de los jueces, las demás penas que se impusieran a los infractores.

Esta orden anulaba cualquiera anterior en sentido contrario y para que nadie alegara ignorancia, se publicaba por bando en Manila, México y Acapulco (70).

(67) Ibidem, arts. 11 y 12.

(68) Ibidem, art. 13.

(69) Ibidem, art. 14.

(70) Ibidem, arts. 15 y 17. 
3.3. Derechos a pagar por el Comercio de Manila y reglas para el retorno a las Islas

El legislador resuelve este asunto de una forma sencilla. Si con el permiso de 300.000 pesos de principal y 600.000 de retorno se pagaban 100.000 pesos en Acapulco, desde ahora se abonaría la cantidad que por prorrateo le corresponda al nuevo permiso de 1.000.000 de pesos. En Madrid se calculaba esta contribución en un $17 \%$. Además se eximía al comerciante de pagar alcabala de la primera venta, aunque sí lo haría de las ventas siguientes. El Rey consideraba que con este sistema se beneficiaban los intereses filipinos, sobre todo si se tenía en cuenta que el real erario costeaba las fábricas, aprestos, tripulación, etc., sin recibir más que 44 ducados por cada tonelada de repartimiento. En cualquier caso, si no se aceptaba esta nueva regulación, se exigiría el pago de todos los impuestos (71).

Se limitaba el retorno de beneficios en metálico a 1.000 .000 de pesos. Si éstos fuesen más, se desquitaría proporcionalmente a los comerciantes, en función de las toneladas que se les repartieron y del valor de sus facturas presentadas en Filipinas. No obstante, se daba la posibilidad de emplear el superávit en frutos y géneros de Nueva España, pagando los derechos acostumbrados. El castellano y los oficiales reales de Acapulco, serían los encargados de que este proceso se cumpla de forma equitativa y sin demora. Incluso se limitaba la ganancia que después de pagados los impuestos, no podría superar el $100 \%$. Para controlar el cumplimiento de esta medida, se obligaba a sacar una licencia para embarcar la plata, que cada comerciante presentaría para su legalización ante el castellano y oficiales reales de Acapulco. El virrey debía encargarse de que estas licencias se expidieran rápida y gratuitamente.

Si las ganancias no alcanzaran el millón de pesos, quedaba totalmente prohibido que los vecinos o residentes en Nueva España pudieran remitir lo que faltase, ni enviar sus mercancías a Filipinas bajo pena de decomiso, más el pago de una multa del $3 \%$ de su valor, si fuere la primera vez; o pérdida de sus bienes y destierro por diez años de las provincias del virreinato, si fuere reincidente. Los jueces y denunciantes serían recompensados con una parte proporcional de lo requisado (72).

(71) Ibidem, art. 4.

(72) Ibidem, arts. 18, 19, 20 y 21. 


\section{Consecuencias de la Real CÉdula de 1734}

En abril de 1735 el virrey acusa recibo de esta cédula (73). Tres meses más tarde Valdés Tamón, gobernador de Filipinas, también escribe al Rey, participándole que la cédula fue muy bien acogida y aceptada en su totalidad por la Ciudad y Comercio. Y haciendo hincapié en la buena voluntad del vecindario expresaba su renuncia altruista al capítulo 10 de la citada cédula -que permitía embarcar la cantidad que faltase hasta completar los 500.000 pesos - para evitar los motivos de queja que pudieran tener los comerciantes españoles (74), ya que serían satisfechas sus aspiraciones de mercado. Sin embargo, éstos siguen insistiendo en que con sólo el comercio de canela, pimienta y clavo, podían los filipinos alcanzar sobradamente la cifra del permiso. Para demostrarlo, enviaban al Rey un estudio económico sobre los gastos y beneficios que ocasionaría el tráfico con las especias (75). Proponen eliminar la competencia para los isleños en la venta de su canela y ante la tesis de que el comercio peninsular no tiene poder para obligar al novohispano a comprar las mercancías del galeón, y que la canela la pueden llevar tanto el navío de permiso inglés como algún barco de la proyectada Compañía de Filipinas (76), responden que lógicamente si Filipinas tiene el monopolio comercial de canela, los mexicanos no tendrán más remedio que comprársela a sus mercaderes. Por otro lado, no había por qué preocuparse tanto por la Compañía de Filipinas, ya que corría el rumor de que sus directores habían desistido de tal empresa, pero en cualquier caso, siempre se le podría solicitar que no perjudicaran a los vecinos de Manila. Igualmente suponen

(73) Carta al virrey de Nueva España al Rey. México, 23 abril 1735. AGI. Filipinas 120.

(74) Carta de Valdés Tamón al Rey. Manila 27 julio 1735. AGI. Filipinas 425.

(75) Vid. nota 50, fols. 33 a 35.

(76) El 26 de abril de 1732, el Rey firma la licencia para que la compañía de D. Manuel Arriaga, navegase de Cádiz a Filipinas, según unas cláusulas determinadas. "Testimonio de la real cédula sobre licencia a D. Manuel Arriaga y Compañía...". AGI. Filipinas 42\%. Sin embargo, este proyecto nunca se hizo efectivo. En 1733 Patiño quiso ponerlo en práctica y aunque esta vez fueron más lejos, su organización fracasó. No entramos en el análisis de este intento, pues se encuentra perfectamente estudiado en la obra de M. a Lourdes Díaz-Trechuelo Spínola, La Real Compañia de Filipinas. Sevilla 1965 que recoge los primeros proyectos para establecer un comercio directo entre la metrópoli y las Islas, como precedentes de la formación de la Compañía en 1785. José Cosano Moyano, en su trabajo "Un nuevo intento del comercio directo con Filipinas: La Compañía de Aguirre, Del Arco y Alburquerque". Anuario de Estudios Americanos. Sevilla, 1978, tomo XXXV analiza la decadencia comercial filipina en la segunda mitad del siglo XVIII a raíz del "Discurso" del marqués de los Llanos y don Pedro Francisco Goozens y el proyecto que en 1766 fue presentado para la formación de la compañía mencionada. 
que el Rey pondrá todos los medios a su alcance para que los ingleses se abstengan de transportar canela (77). Tras otra serie de consideraciones, solicitaban se retire a Filipinas el permiso para comerciar con seda y listonería chinas, en atención al hundimiento del comercio peninsular (78).

A pesar de todo, el comercio tradicional con Acapulco se mantuvo, con la continua insistencia de los vecinos de Manila para que se les aumentara su permiso. En 1771 el Consulado de Manila redactó un informe sobre la decadencia de su comercio, indicando los remedios que consideraba oportunos, entre ellos, el aumento del permiso en 300.000 pesos, sin incrementar los impuestos a pagar en Acapulco. El expediente pasó a España siendo gobernador Simón de Anda y Salazar (79). Sin embargo, a pesar de las reiteradas peticiones, estaba claro, incluso para los propios comerciantes filipinos, que el aumento, no subsanaría el quebranto económico que padecían las Islas, incapaces de autoabastecerse, dependiendo constantemente de las ferias de Acapulco. No será hasta el último tercio del siglo XVIII, cuando se empiece a vislumbrar un alza importante en la economía de las Islas, a raíz de la creación de la Real Compañía de Filipinas en 1785 que fomenta la agricultura (80) pero, sobre todo, con el decreto de libre comercio dado en 1789, por el que se abría el puerto de Manila a los barcos extranjeros, con lo que se estimuló la actitud de los naturales, modificando radicalmente la balanza comercial de las Islas, "que no sólo dejaron de resultar carga onerosa para España, sino que comenzaron a producir copiosas rentas» (81).

\section{Comparación ENTRE la ReAl CÉdula DE 1720, El REglamento DE 1726 Y LA REAL CÉDULA DE 1734}

En una primera lectura de estas tres reales órdenes resaltan, en primer lugar, dos grandes diferencias; una respecto a la cuan-

(77) Vid. nota 50, fols. 32-32vto.

(78) Ibidem, fols. 41-41vto.

(79) M. ${ }^{\text {a }}$ Lourdes Díaz-Trechuelo, "El comercio de Filipinas en la segunda mitad del siglo XVIII". Revista de Indias, Madrid, 1963, nos 93-94, pág. 473.

(80) Para todo lo relacionado con la Real Compañía de Filipinas ver, DíazTRECHUELO [76].

(81) M. a Lourdes Diaz-Trechuelo Spínola, "Manila Española: Notas sobre su evolución Urbana". Revista de Estudios Americanos. Sevilla 1965. Vol. IX, no 44, págs. 457-458.

Sobre la etapa de comercio libre en las Islas, ver la misma autora, "Manila Puerto franco. El libre comercio de Filipinas en la última década del siglo XVIII». Proceedings of XXXVIII International Congress of Americanists. Stutgart-München, 1968, vol. III, págs. 501-508. 
tía del permiso: 300.000 pesos de principal y 600.000 de retorno en 1720; 4.000 piezas para vender en Acapulco, y embarque de las ganancias obtenidas por su venta, hasta un límite de 1.200.000 pesos en 1726; mientras que en 1734, se disminuye el retorno en 200.000 pesos, siendo el principal de 500.000. Otra discrepancia, sería la calidad de los géneros a traficar. La prohibición de comerciar con seda china dada en la real cédula de 1720, queda anulada en las otras dos. En segundo lugar llama la atención la similitud, salvando las diferencias anteriores, entre el articulado de las cédulas de 1720 y 1734.

En un examen más detenido de estos tres documentos, se observan algunas variantes más.

La regulación del permiso de carga, que en 1726 se hace por piezas, se organizaba por facturas en 1720 y 1734 .

La numeración de comerciantes la efectúa, en 1726 la Junta de Repartimiento, con lo que a los interesados, caso de sentirse agraviados, sólo se les da opción de recurso ante la Audiencia, excluidos los ministros que intervinieron en ella. Por el contrario, tanto en 1720 como en 1734, la numeración la hace la Ciudad de Manila, dejando a la Junta sólo la capacidad de distribuir el buque. De esta forma, los comerciantes de Manila, tienen la ventaja de un doble recurso. A la Junta en primera instancia, si el contencioso es causado por la numeración, y a la Audiencia, si lo tienen con la Junta.

Sobre la composición de la Junta de Repartimiento, sólo hay datos en las cédulas de 1726 y 1734. Las personas que la integran son las mismas en ambos casos, pero mientras que el compromisario y el regidor que participan son en 1726 los de mayor antigüedad, en 1734 lo harán por riguroso turno anual.

En 1726, se abren inconscientemente las puertas al fraude, al permitirse la cesión de la boleta. Esta práctica conllevaba la de negociar y especular a costa del espacio del galeón, ya que indudablemente, había quienes sacaban más rentabilidad a la venta de su porción, que a la inversión en mercancías para un tráfico lleno de considerables riesgos, tanto por la larga duración del viaje (con lo que podían estropearse los géneros, el navío ser atrapado por algunos piratas de los que circundaban la zona, etc.). Otra dificultad para estas personas era la ignorancia del estado de la feria en Acapulco, de cuya información sólo disponían los grandes comerciantes, con representantes en la capital novohispana. En definitiva, se posibilita el monopolio comercial. Esta norma, que había sido derogada en 1720, vuelve a anularse 
en 1734. En ambos casos, se ordena la devolución de todas las acciones del buque que los favorecidos no ocupen personalmente, a la Junta de Repartimiento para su redistribución, excepción hecha de los pobres y viudas. Esta excepción no se contempla, al menos explícitamente, en la cédula de 1720.

Por otra parte, el que en 1726 se de participación en el buque a los eclesiásticos nos hace sospechar que podía haber infracción de la norma general - prohibición del tráfico con capital mexicano- por tener posibilidad de pasar mercancías y plata, propiedad de sus hermanos de Orden en México. Esto no sucede en las otras dos reales cédulas, que prohíben incluir al clero en el repartimiento. En ellas, también se anula la oportunidad de traficar para los oficiales de las naos ya que los excluye del reparto; por el contrario, en 1726, tenían reservado espacio para cargar 200 piezas. Los que sí tenían derecho a la participación en el buque, en los tres casos, eran los miembros de la tripulación; pero si en 1720 y 1734 se les medía a todos por el mismo rasero, permitiéndoles llevar a cada uno, una caja de mercancías por valor de 30 pesos en Filipinas, en 1726, la caja tendría mayor o menor volumen, dependiendo del empleo de cada uno.

También hay disparidad de criterios, cuando se habla del embarque de géneros: En la cédula de 1720 se exige abrir algunos fardos al azar para comprobar si hay contrabando, lo cual no se menciona en ninguna de las otras dos. En el Reglamento de 1726, se establece un sistema de control escalonado, en el que intervienen en primer lugar, el fiscal, el maestre, el compromisario y el regidor más antiguo, presentes en el momento de la carga; después, una vez cargado el galeón, actuarían los interventores visitando el navío. Por el contrario, en las otras dos órdenes el control del fraude se deja sólo en manos del fiscal y de los oficiales reales, pues ellos asisten al embarque de mercancías e inspeccionan después las naos.

Las competencias del maestro de navío, son prácticamente iguales en los tres documentos, aunque el libro de sobordo, que debía formar en 1726, se debe hacer por duplicado en 1720 y 1734.

Referente a la descarga en Acapulco sólo en el Reglamento de 1726 se menciona la oportunidad de que el representante del Consulado de Cádiz esté presente en la misma, aunque no por ello hay que pensar, que se prohíba su asistencia en las otras dos fechas.

Tampoco se menciona en 1726 la posible recompensa, para el 
denunciante del contrabando y el juez que llevase la vista, recompensas que en las otras dos órdenes son idénticas, y que están muy bien detalladas. Este premio es más que probable que no existiese en 1726, ya que el hecho de que en 1734 se vuelva a insistir en la prohibición dada en 1720 , sobre no admitir «manifestaciones» o pagos de derechos doblados, por lo encontrado fuera de registro, nos sugiere que ésto se hacía en 1726, con lo cual no habría carga que repartir entre el juez y el acusador.

Se ponen por tanto más cortapisas al fraude en las cédulas de 1720 y 1734 que en 1726, pues al permitir pagar impuestos dobles, serían muchos los comerciantes que se arriesgaran a pasar contrabando, puesto que sólo representaría una merma insignificante en la cuantiosa ganancia que les dejaba la mercancía, caso de que se descubriese.

En cuanto a los derechos a pagar por el comercio filipino mientras que en 1726 se establece para cada producto, además del $5 \%$ de almojarifazgo una cantidad fija por cada nave que llegase a Acapulco, en 1720 y 1734, se ordena un sistema de prorrateo (17\% del retorno permitido), más 44 ducados por tonelada de buque.

En la legislación sobre el retorno de los beneficios a las Islas se advierten diferencias notables. En 1720 y 1734, no se permite bajo ningún concepto llevar a Filipinas más plata que la autorizada en el permiso. Por el contrario en 1726, no sólo se permite a quienes no vendieron sus mercancías en un año, cargar en el siguiente el dinero obtenido por ellas, sino que se da la posibilidad de retornar las ganancias retenidas en Nueva España antes de la publicación de este reglamento, justificando formalmente ante el virrey ser vecinos de Manila y tener bloqueadas tales cantidades por falta de permiso, y abonando un $10 \%$ de su importe.

Por último, mientras que en 1726, únicamente se exigía a cada comerciante juramento solemne de ser suyo todo lo que embarcaba en el regreso, en 1720 y 1734 se les obliga a sacar licencias.

Igualmente, varían las penas aplicadas a los infractores. Multa por el valor del fraude más el $3 \%$, y el destierro perpetuo de las islas si fuese soltero, o exclusión de por vida en el repartimiento, si estuviese casado, en 1726; en 1720 y 1734, se castiga la falta con el pago del $3 \%$ del importe, si es la primera vez que delinque; y en el caso de reincidencia, con la pérdida de todos sus bienes y el destierro por diez años de las provincias de Nueva España. 